\title{
Tulane
}

Tulane Economics Working Paper Series

\section{Honesty or Dishonesty of Taxpayer Communications in an Enforcement Regime}

\author{
James Alm \\ Department of Economics \\ Tulane University \\ jalm@tulane.edu
}

\author{
David M. Bruner \\ Department of Economics \\ Appalachian State University \\ brunerdm@appstate.edu
}

\author{
Michael McKee \\ Department of Economics \\ Appalachian State University \\ mckeemj@appstate.edu
}

Working Paper 1620

December 2016

\begin{abstract}
In many settings the true likelihood of capture when engaging in an illegal activity, such as tax evasion, is not well known to an individual. "Official" statements from the tax administration regarding enforcement effort provide some information. In addition, "informal", or "unofficial", communication among taxpayers can supplement these official announcements, but individuals do not know with certainty whether such unofficial information is honest (or accurate) versus dishonest (or inaccurate). We examine the truthfulness of an individual's revelation of unofficial information to other individuals, along with the factors that affect any revelation, focusing on the intrinsic motivations for revelations. Our experimental design allows us to examine the type and the honesty of messages that an individual chooses to send to other individuals regarding their own audit outcome and their own compliance behavior. Our results indicate that most individuals send accurate messages about their own audit outcomes and their own compliance behaviors. Nevertheless, many individuals are also systematically dishonest about being audited; that is, we observe a significant tendency for individuals to claim that they were audited when they were not. We also observe a strong interaction between individuals' audit outcomes and their compliance behaviors, so that individuals who engaged in tax evasion and who were audited were more truthful in their communications than those whose tax evasion went undetected.
\end{abstract}

Keywords: Tax compliance, Tax audits, Information, Honesty, Experimental economics. JEL codes: H2, H26, C91 


\title{
Honesty or Dishonesty of Taxpayer Communications in an Enforcement Regime
}

\author{
James Alm $^{\mathrm{a}, *}$, David M. Bruner ${ }^{\mathrm{b}}$, and Michael McKee ${ }^{\mathrm{c}}$ \\ ${ }^{a}$ Department of Economics, 208 Tilton Hall, Tulane University, New Orleans, Louisiana 70118 \\ USA. Email: jalm@tulane.edu; tel.: +1 504862 8344; fax: +1 5048655869. \\ ${ }^{\mathrm{b}}$ Department of Economics, Appalachian State University, 3106 Peacock Hall, 416 Howard \\ Street, Boone, North Carolina 28608 USA. Email: brunerdm@appstate.edu. \\ ${ }^{c}$ Department of Economics, Appalachian State University, 3098 Peacock Hall, 416 Howard \\ Street, Boone, North Carolina 28608 USA. Email: mckeemj@appstate.edu. \\ * Corresponding author.
}

\section{$\underline{\text { Abstract }}$}

In many settings the true likelihood of capture when engaging in an illegal activity, such as tax evasion, is not well known to an individual. "Official" statements from the tax administration regarding enforcement effort provide some information. In addition, "informal", or "unofficial", communication among taxpayers can supplement these official announcements, but individuals do not know with certainty whether such unofficial information is honest (or accurate) versus dishonest (or inaccurate). We examine the truthfulness of an individual's revelation of unofficial information to other individuals, along with the factors that affect any revelation, focusing on the intrinsic motivations for revelations. Our experimental design allows us to examine the type and the honesty of messages that an individual chooses to send to other individuals regarding their own audit outcome and their own compliance behavior. Our results indicate that most individuals send accurate messages about their own audit outcomes and their own compliance behaviors. Nevertheless, many individuals are also systematically dishonest about being audited; that is, we observe a significant tendency for individuals to claim that they were audited when they were not. We also observe a strong interaction between individuals' audit outcomes and their compliance behaviors, so that individuals who engaged in tax evasion and who were audited were more truthful in their communications than those whose tax evasion went undetected.

Keywords: Tax compliance; Tax audits; Information; Honesty; Experimental economics. PsycINFO classification: 2360; 2910; 3020; 3040; 3120.

JEL classification: $\mathrm{H} 2, \mathrm{H} 26, \mathrm{C} 91$.

Acknowledgements: The research reported here was partially funded by the Internal Revenue Service (TIRNO - $07-\mathrm{P}-00683$ ) and the Social Sciences and Humanities Research Council (Canada) RT733923. The views expressed are those of the authors, and do not reflect the opinions of the IRS or of the Social Sciences and Humanities Research Council. The software for these experiments was designed by the authors and programmed by Michael Jones of Bridgewater State University in Bridgewater, MA. An earlier version of this paper was presented at the 2014 conference "Taxation, Social Norms and Compliance" in Nuremberg, Germany, and we are grateful to Joerg Paetzold and other conference participants for many helpful comments. We are also grateful to Erich Kirchler, Martin Kocher, and three anonymous referees for many useful suggestions. 


\section{Introduction}

The basic economics of crime approach (Becker, 1968) models the decision to engage in illicit activity as a gamble, in which a rational individual weighs the expected benefits of a successful crime against the risky prospect of detection and punishment. This model assumes the individual knows the probability of detection and the associated penalty of the illegal activity. However, in many settings the true likelihood of capture when engaging in an illegal activity is unknown to the individual, and must be inferred based on various sources of information. Consider the case of tax evasion. Information on audit rates may come from several sources. "Official" statements from the tax administration to taxpayers about enforcement effort provide some information, but are not routinely used by government agencies. More commonly, taxpayers rely on "unofficial" (or "informal") sources of communication. Such informal communication is not limited to tax evasion. Every day people exchange unofficial information regarding the enforcement of regulations, ranging from traffic laws, environmental policies, city ordinances, corporate policies, health care, and the like, often in an effort to ascertain the probability of violating those regulations and to see how far they can "bend" the rules. ${ }^{1}$

However, individuals do not know with certainty whether such unofficial information is accurate or not. After all, the value of information lies in its truthfulness. What factors affect the individual's decision to reveal honest and accurate - or dishonest and inaccurate - information?

\footnotetext{
${ }^{1}$ Such informal networks can be discussions with friends and neighbors, trade journals such as those produced for professional occupations (e.g., physicians, engineers), and newspaper accounts. A recent example includes informal online networks developed by Uber drivers to pool information on enforcement, taxation, and other regulations (Oei and Ring, 2016).
} 
In recent years, a growing literature has emerged to address this question, including the potential roles of gender, age, income, group size, religion, and priming (Gneezy, 2005; Dreber and Johannesson, 2008; Childs, 2009; Lundquist et al., 2009; Sutter, 2009; Holm and Kawagoe, 2010; Conrads et al., 2013; Cappelen, Sørensen, and Tungodden, 2013; Gneezy, Rockenbach, and Serra-Garcia, 2013; Gylfason, Arnardottir, and Kristinsson, 2013; Cojoc and Stoian, 2014; Glätzle-Rützler and Lergetporer, 2015; Gächter and Schulz, 2016). ${ }^{2}$ In general, these studies reveal that individuals have a strong inclination to communicate honestly with each other, despite having clear incentives to be deceptive. In fact, a majority of people tend to exhibit "lie aversion" when it comes to communication of basic information (Gneezy, 2005).

However, an unresolved question is whether informal communication regarding enforcement effort exhibits this same tendency towards honesty, given the absence of clear monetary incentives for honesty. It is this question that we examine. Specifically, we examine the truthfulness of an individual's revelation of unofficial information to other individuals, along with the factors that affect any revelation.

Examining the accuracy of informal peer communication is important, due to its potential to affect subsequent compliance behavior. Indeed, Alm, Jackson, and McKee (2009) conducted an experiment specifically designed to investigate the effect of such information on reporting compliance. Their results showed that informal communication among peers informs compliance behavior in the absence of official information from the tax authority and that this informal communication can serve to augment official information; that is, when the informal messages suggest that the audit rate is relatively high, compliance levels increase, and vice versa.

Still, it is unclear why compliance may be affected when official information is replaced or augmented with informal communication. If people communicate honestly, as behavior in

\footnotetext{
${ }^{2}$ See Rosenbaum, Billinger, and Stieglitz (2014) for a recent survey of the experimental literature.
} 
many experiments suggests, then such informal communication should be a perfect substitute for official information. As a result, there should be no incremental effect on compliance when official information is available. However, this result depends on the unofficial information being truthful enough to be reliable.

We examine the truthfulness of informal peer communication utilizing a subset of the experimental data of Alm, Jackson, and McKee (2009) that pertain to individual information disclosure about their own audit outcomes and their own tax reporting behaviors in the current decision round. In their laboratory experiment, taxpayers were offered as a treatment the opportunity to communicate via a number of possible messages sent within their cohort, both about their own outcome of a random audit (e.g., "I was not audited") and about their own compliance behavior (e.g., "I was not audited and did not report all of my taxes"). Importantly, the information that any taxpayer sent to others could be honest (or accurate) information, or it could be dishonest (or inaccurate) information; that is, there was no restriction on the honesty/accuracy of messages individuals were allowed to send to others, and individuals could also choose to send no message at all. ${ }^{3}$ The focus of Alm, Jackson, and McKee (2009) was on the impact of official versus unofficial information. Our focus here is on the honesty or dishonesty of unofficial information, together with the factors that affect any disclosure. We use their data to examine the accuracy of messages that individuals chose to send to others regarding their own audit outcomes and compliance behaviors. After all, both types of information can

\footnotetext{
${ }^{3}$ We treat as equivalent in our discussion "accurate" and "honest" declarations, largely because our experimental design allows us to determine unambiguously that an "accurate" declaration is equivalent to an "honest" declaration. For a similar reason, we use the terms "inaccurate" and "dishonest" interchangeably.
} 
influence the compliance decision of others through the formation of beliefs regarding the audit policy, as well as through the social norm of compliance. ${ }^{4}$

We formulate a model of the role that both types of information may play in whether an individual decides to engage in tax evasion and in how the actual audit policy interacts with the accuracy of informal communication. We then investigate whether individuals reveal honest/accurate or dishonest/inaccurate information.

The experimental design follows the elements of much research on voluntary tax compliance (Becker, Buchner, and Sleeking, 1987; Alm, Jackson, and McKee, 1992; Alm, McClelland, and Schulze, 1992), incorporating additional features to improve parallelism with taxpayers' decision making in the naturally occurring world. ${ }^{5}$ Participants earn income by performing a task (rather than receiving an endowment), they disclose income, and they face an audit process similar to that in the naturally occurring setting. The experimental instructions and the computer interface utilize tax language. The stakes are small, but the decision is simplified implying that the ratio of decision costs and rewards parallels the naturally occurring setting (Smith and Walker, 1993). A key addition to earlier designs for our present research is that taxpayers may not be well informed by the tax authority as to the likelihood of an audit but that they have an opportunity to inform others of their audit experiences and compliance behaviors, as well as to learn from information provided by others.

\footnotetext{
${ }^{4}$ Indeed, Alm, Jackson, and McKee (2009) present evidence that suggests that both types of information affect compliance behavior.

5 Experiments designed to inform policy must satisfy Smith's (1982) precept of “parallelism”, which is satisfied when the experimental setting captures the "essential" elements of the decision problem faced in the naturally occurring setting. It is neither necessary nor desirable for the experiment setting to implement all of the complexity of the naturally occurring setting (Plott, 1987). Beyond parallelism, it is desirable that the experiment meet the conditions for external validity. Alm, Bloomquist, and McKee (2015) compare compliance behavior from field data with behavior from various subject pools in laboratory experiments similar to the experiments here. They find that the behavioral patterns of subjects in the laboratory conform to that of individuals making a similar decision in naturally occurring settings, and also that the behavioral responses of students are largely the same as non-students in identical experiments.
} 
It should be recognized that, in contrast to previous studies of honesty, there were no monetary incentives for truthful disclosure of tax reporting behavior or audit experience in the experiment; that is, we focus on "intrinsic motivations" (e.g., the desire to undertake an activity for its own sake), not "extrinsic motivations" (e.g., choosing an activity because of incentives that come from outside the individual, such as financial rewards). ${ }^{6}$ We deliberately chose this feature in large part because the absence of monetary incentives for honesty is an important feature of many naturally occurring settings in which individuals send signals to others and/or engage in various types of pro-social behavior. For example, individuals share their experiences with products (e.g., Consumer Reports), they report their ratings of restaurants and other service providers through social media, and so on. An important issue in all of these settings is whether the information is reliable, and this aspect is of interest precisely because there is no direct monetary incentive to report truthfully, or even to report at all.

The results of our analysis suggest that individuals mostly send truthful messages about both their audit outcomes and their compliance behaviors, despite a lack of financial incentive to convey truthful - or even any - information. Indeed, we find that more than 80 percent of the time subjects chose to send a message and that more than 80 percent of messages report accurate information to fellow taxpayers, results that are consistent with evidence on lie aversion. Nevertheless, our results also indicate that many individuals are systematically dishonest about their audit outcome and compliance behavior. We observe a significant tendency for individuals to claim that they were audited when they were not. Consistent with the theoretical framework, the upward bias in the reported audit rate appears to systematically increase as the likelihood of being audited approaches zero. Although individuals tend to be honest about their compliance

\footnotetext{
${ }^{6}$ The literatures on intrinsic versus extrinsic motivations are quite large. In the specific context of tax compliance, see especially Frey $(1992,1997)$, Kirchler (2007), and Torgler (2007).
} 
behavior when they send messages, they also tend to be less willing to share information regarding their compliance behavior. Moreover, dishonest communication regarding evasion inflates the reported compliance rate. Both forms of dishonesty are consistent with the increase in compliance reported by Alm, Jackson, and McKee (2009).

\section{Theoretical Framework}

The principle economic model of income tax evasion (Allingham and Sandmo, 1972) is based on the rational criminal framework developed by Becker (1968), and focuses on the risk associated with underreporting income. In its simplest form, an individual is assumed to receive an initial endowment of income $Y$, and must choose how much of this income to declare to the tax authorities. The individual pays taxes at rate of $t$ on every dollar $R$ of income that is reported, while no taxes are paid on underreported income. However, the individual may be audited with a fixed, predetermined probability $p$; if audited, then all underreported income is discovered, and the individual must pay a penalty at rate $f$ on each dollar of taxes that is underreported. Assuming that the individual has well-defined preferences that are linear in income, then the taxpayer's objective is to choose reported income $R$ to maximize expected income, $E[I]$, or

$$
E[I]=Y-t R-p f t(Y-R)
$$

where $E$ is the expectation operator. ${ }^{7}$ This framework implies all-or-none behavior, depending on the levels of $p$ and $f$. The individual will report all income if

$$
p f t>t
$$

\footnotetext{
${ }^{7}$ Allingham and Sandmo (1972) analyze the compliance decision in an expected utility framework, which incorporates risk preferences.
} 
(or, more simply, if $p f>1$ ), while the individual will report zero income if the inequality is reversed. The enforcement regime (e.g., the audit probability $p$ and the penalty rate $f$ ) therefore determine the optimal declared income.

This standard model has been modified in a number of ways. ${ }^{8}$ However, to date there have been few investigations of the characteristics and the spillover effects of communication regarding enforcement. ${ }^{9}$ Indeed, it is often the case that taxpayers are unaware of the enforcement regime chosen by authorities. While the penalty rate for evasion may be publicized and therefore known, the audit probability is usually a closely guarded secret. In such situations, taxpayers must make decisions based on their own beliefs. Even if the audit probability is officially announced, taxpayers may report income based on their own beliefs, as influenced by factors such as their own personal experience and the experiences of others. The effect of information spillovers through such unofficial communication channels depends upon the accuracy of the information. What is missing from this literature, we believe, is an analysis of the propensity of individuals to report honestly and accurately their own experiences with the enforcement regime. To examine this issue, we focus on the probability of audit; a similar analysis applies to the penalty rate.

Suppose that the taxpayer does not know the probability of an audit and must form a belief about its value. Suppose further that each taxpayer obtains a sample of $N$ observations based on his or her own experience and the communicated experiences of other taxpayers. Denoting the experience of taxpayer $i$ with an audit as $x_{i}=1$ and the experience of the taxpayer

\footnotetext{
${ }^{8}$ See Andreoni, Erard, and Feinstein (1998), Slemrod and Yitzhaki (2002), Kirchler (2007), Torgler (2007), Sandmo (2012), and Alm (2012) for a discussion of the standard evasion model and its many variants. See especially Alm and Torgler (2011) for ways in the standard evasion model can be modified to incorporate the "ethics" in individual motivations.

${ }^{9}$ See Andreoni (1991) for an analysis of the concept of "reasonable doubt" and its role in the decision of a juror to convict or acquit. Also, see Alm and McKee (2004, 2006), Alm, McClelland, and Schulze (1992, 2009), and Alm, Bloomquist, and McKee (2016) for studies that provide evidence on the central role of taxpayer communication in tax compliance decisions.
} 
with no audit as $x_{\mathrm{i}}=0$, this communication results in a sample of outcomes $x_{1}, x_{2}, \ldots, x_{N}$ for $i=1$, 2, ...N taxpayers, where $x_{i} \in\{0,1\} \forall i$ is distributed as a Bernoulli random variable. The probability of observing $X=\sum_{i=1}^{N} x_{i}$ audits out of $N$ trials is then given by $f(X \mid p) \propto$ $p^{X}(1-p)^{N-X}$. Let $F(p)$ denote the distribution of each taxpayer's prior belief about the value of $p$. For convenience, assume that $F(p)$ is a beta distribution with parameters $\alpha$ and $\beta$, so that $F(p) \propto p^{\alpha-1}(1-p)^{\beta-1}$. Then the posterior distribution of beliefs is given by $\varepsilon(p \mid X, N) \propto$ $p^{\alpha+X-1}(1-p)^{\beta+N-X-1}$ (DeGroot, 1970). Thus, each taxpayer's expectation of the probability of an audit is given by

$$
\hat{p}=\frac{\alpha+X}{\alpha+\beta+N}
$$

The parameters $\alpha$ and $\beta$ of the prior belief distribution capture any official information provided by the tax authority. Such official information serves to complement any unofficial information reported by other taxpayers, along with the taxpayer's own experience.

Of course, this expectation assumes honest transmission of information. If a taxpayer's sample is composed of self-reported observations from other agents, then the reliability of the information becomes uncertain. Self-reported observations create a potential for dishonest and inaccurate information to enter the taxpayer's sample. Such reports can be in either direction; that is, denoting the dishonest report of taxpayer $j$ as $d_{j}$, a taxpayer can report $d_{j}=0$ when $x_{j}=1$ and vice versa. Let $n_{1}$ and $n_{2}$ denote the number of honestly and dishonestly self-reported observations, respectively, such that $N=n_{1}+n_{2}$. Hence, each taxpayer's belief of the probability of an audit can now be written as

$$
\hat{p}=\frac{\alpha+X^{\prime}+D}{\alpha+\beta+N}
$$


where $X^{\prime}=\sum_{i=1}^{n_{1}} x_{i}$ and $D=\sum_{j=1}^{n_{2}} d_{j}$, such that $i \neq j$ denote the number of honestly and dishonestly reported audits, respectively. To see the effect of dishonest reporting on taxpayer beliefs, consider the bias of the estimator in equation (4), which is given by

$$
\operatorname{Bias}(\hat{p} \mid p)=\frac{\alpha(1-p)-\beta p+n_{2}(1-2 p)}{\alpha+\beta+N}
$$

According to equation (5), there are two cases where beliefs are asymptotically unbiased. The first case occurs when everyone reports audits honestly and accurately (i.e., $n_{1}=N$ and $n_{2}=0$ ). In this case, equation (4) is equivalent to equation (3), where beliefs are based on the actual audit results. The second case is when the audit probability is 50 percent (i.e., $p=\frac{1}{2}$ ). In this case, dishonest reports will just offset each other since every time a taxpayer claims to have been audited when they were not (i.e., $d_{j}=1$ when $x_{j}=0$ ) another taxpayer will claim not to have been audited when they actually were (i.e., $d_{j}=0$ when $\left.x_{j}=1\right) .{ }^{10}$ Since the likelihood of an audit is typically less than 50 percent, equation (5) implies that beliefs will be asymptotically biased upward. Moreover, holding $\alpha$ and $\beta$ fixed, the bias increases as $p$ approaches zero.

This reasoning suggests our first hypothesis:

Hypothesis 1: As the likelihood of an audit declines to zero, the amount by which the reported audit rate exceeds the actual audit rate (i.e., the upward bias) will increase.

This is because there will be more opportunities for taxpayers to claim to have been audited when they were not audited (i.e., $d_{j}=1$ when $x_{j}=0$ ). As a result, this upward bias in the perceived likelihood of audit will induce increased compliance, in accordance with equation (2).

However, peer communication is not limited to one's outcomes, but may also convey information regarding one's behavior. This can in turn influence the compliance behavior of others by establishing a social norm of compliance (Alm, McClelland, and Schulze, 1999;

\footnotetext{
${ }^{10}$ This assumes dishonesty is a symmetrically distributed random variable.
} 
Torgler, 2002; Wenzel, 2004, 2005; Kirchler, 2007). To illustrate, assume that a taxpayer incurs a loss in income that occurs when he or she reports income that deviates from a perceived social norm of compliance, where the social norm is some fraction $\varphi$ of income, or $\varphi Y$, where

$$
\varphi \equiv \sum \frac{\widehat{R}}{Y},
$$

so that $\varphi$ measures the average perceived compliance rate of the taxpayer's peers. Assume also for simplicity that the total loss in income from deviating from the social norm increases by a scalar $\lambda$ times the square of the deviation of reported income $R$ from the social norm, according to $\left[\lambda(\varphi Y-R)^{2}\right]$. This loss in income can be the result of social sanctions (e.g., ostracism) that lead to a lost stream of future benefits from exchange with members of one's group, of emotional dismay, or of regret, guilt, or shame (Erard and Feinstein, 1994).

The taxpayer's objective is now to maximize:

$$
E[I]=Y-t R-\hat{p} f t(Y-R)-\lambda(\varphi Y-R)^{2} .
$$

Regardless of the precise form of the loss in income, the influence of the perceived social norm on compliance behavior is readily apparent: as the perceived average compliance rate $\varphi$ increases and thus establishes a social norm of compliance, the optimal compliance of a taxpayer will increase, and vice versa. Of course, a taxpayer can be dishonest regarding his or her compliance behavior, so that $\hat{R} \neq R$. Moreover, it is easy to imagine that an individual may be reluctant to honestly reveal information regarding evasion, as such activity is illegal and may be seen as violating the social norm of compliance. Indeed, it is our hypothesis that taxpayers will be systematically dishonest about evasion, such that the compliance rate as reported by the individual will exceed the individual's actual compliance rate.

This reasoning suggests our second hypothesis:

Hypothesis 2: The reported compliance rate will exceed the actual compliance rate. 
Such dishonesty will inflate the social norm and thereby increase overall compliance.

Overall, we have established two possible means by which dishonest peer communication can potentially result in an increase in compliance. Taxpayers may be dishonest about their own audit outcomes, which may result in an upward bias in the perceived likelihood of an audit. Taxpayers may also be dishonest about their own compliance behavior, which can inflate the social norm of compliance. These two forms of dishonesty are neither mutually exclusive nor are their effects substitutes in the compliance decision. Indeed, it is possible that both forms of dishonesty exist and potentially reinforce each other. It is an open empirical question as to what extent taxpayers are dishonest or honest across these two dimensions. The next section presents our experimental design to examine this issue.

\section{Experimental Design}

We use a subset of the experimental data from Alm, Jackson, and McKee (2009), so our discussion of the experimental design follows closely their discussion. The design captures the essential features of the voluntary income reporting and tax assessment system used in many countries. ${ }^{11}$ Human participants in a controlled laboratory environment earn income through their performance in a task and decide how much of this income to report to a tax agency. Taxes are paid on reported income. However, unreported income may be discovered via a random audit, and the participant must then pay the unpaid taxes plus a fine based on the unpaid taxes. This income earning, income reporting, audit, and penalty process is repeated for 30 decision rounds, each representing a tax period. All audits investigate only the current period disclosure. At the completion of the experiment, all participants are paid in cash their accumulated earnings converted to U.S. dollars. The currency used is called "lab dollars", and participants are told that

\footnotetext{
${ }^{11}$ All experimental instructions (including all screen images) are available upon request.
} 
all lab dollars earned during the session will be redeemed for cash at the end of the session at a fixed conversion rate of 90 lab dollars per 1 U.S. dollar.

The earnings task requires that the participants sort the digits 1 through 9 into the correct ascending order from a randomized order presented in a 3 by 3 matrix. Participants do this by pointing the computer mouse and "clicking" on the numbers in the correct sequence. ${ }^{12}$ A counter on the screen shows the elapsed time from when the first number is "clicked" to the point when all nine have been ordered. Actual income is determined by the relative speed of performance, with the fastest performer receiving the highest income and the slowest performer receiving the lowest income. Once all participants have completed the income task, they are informed via the computer of their income for the round and presented with a screen that resembles a tax form in which they may report their income. This screen informs the participants of the tax policy information in effect for the session.

We have partitioned the sessions of Alm, Jackson, and McKee (2009) into two treatments (Table 1), in which the official audit policy is announced (Treatment A) or is not announced (Treatment B). The official audit policy (e.g., the audit rate) is announced to all subjects in Treatment A prior to the tax filing decision. This official information is assumed to be treated as credible by the taxpayers, as it is reinforced by the computerized audit process described below. In Treatment B, the official audit policy is not announced. In both treatments, "unofficial" information is available in the form of messages that each subject is allowed to send to other subjects regarding his or her own audit outcome and compliance behavior. Hence, subjects may learn some audit outcome information from their own experiences and from the experiences

\footnotetext{
${ }^{12}$ On their computer screen a 3 by 3 matrix with the digits in random order appears on the right side of the screen and as the numbers are "clicked" they appear in a 3 by 3 matrix on the left side of the screen.
} 
disclosed by others. In addition, social norms regarding compliance behavior can develop through peer communication.

In all sessions, subjects are partitioned into groups ranging in size from six to eight participants with whom they are permitted to communicate at the end of the decision round. ${ }^{13}$ For the communication mechanism, the participants are permitted to send one of seven predetermined messages via the computer in each round to all persons in their group; subjects can also choose not to send any message. The possible messages are reported in Table 2. Note that there is no financial incentive to report the truth or to lie. ${ }^{14}$ The behavior of others cannot affect an individual's probability of audit, and there is no public good financed by the tax payments. Thus, the only motivation in this setting is an intrinsic motive.

The information process is constructed as follows. After the audit process is completed, the taxpayers are presented a new screen that provides the earnings and audit outcome summary for the round. Each participant then may choose to send one of the seven predefined messages reported in Table 2 (including the possible choice of "No message", termed Message 1) to members of their group. After all taxpayers have sent a message, they receive further feedback in the form of a table that reports the number of persons sending each of the messages. Since the actual number of audits is not reported to the subjects, there is no means by which the subjects can verify whether any of this unofficial information is truthful. ${ }^{15}$ Indeed, the experimental setting does not impose the requirement that the information be truthful. Our primary interest in the subsequent analysis is the accuracy of these messages.

\footnotetext{
${ }^{13}$ Group sizes varied slightly according to the no-show rates across sessions. There were always two groups per session. The minimum group size of six and the anonymity of the information disclosure make it doubtful that there are reputation effects.

${ }^{14}$ It is common knowledge that the audit mechanism is purely random so there is no strategic advantage from lying to have another person selected for an audit.

${ }^{15}$ In the field, individuals may know actual audit results, and they may also receive information from individuals whom they know or know of. However, the numbers of taxpayers in the field are so large that it is unlikely that one could combine these data to know whether the person with whom they were communicating spoke the truth.
} 
In all sessions subjects are informed of the tax rate and the fine rates; the tax rate is set at 0.35 , the fine rate is set at 150 percent, and both are fixed for all rounds. ${ }^{16}$ As previously noted, there is no public good financed by the tax payments, which mitigates any potential extrinsic incentive associated with peer communication. The probability of audit is chosen from several levels $(0.05,0.10,0.30$, and 0.40$)$, and is changed once (beginning in round 16) so that each participant faces two of the four possible audit probabilities. ${ }^{17}$ These probabilities are applied for both of the treatments shown in Table 1. In approximately half of the sessions the audit probability increased, to mitigate possible order effects.

The process of determining who is audited is generated by a computerized draw. In sessions in which the audit probability is announced, the participants are presented with an animated (computerized) representation of a bucket of colored balls from which a draw is made. Each taxpayer is audited independently. When the audit probabilities are not announced, the bucket does not appear on the screen; the taxpayer simply receives a message that reports whether he or she was audited or not.

To address the level of truthful information disclosure, we use the information signals sent by 102 subjects over 30 rounds of each treatment, which gives a total of 3060 possible messages; excluding the "No message" signal, we have 2516 messages. Since we know, by virtue of the experimental design, what the actual audit outcome and compliance behavior were for each subject, we are able to determine the honesty/accuracy or dishonesty/inaccuracy of each signal.

\footnotetext{
${ }^{16}$ The tax rate and the penalty rate are fixed throughout the experiments so that we may focus on the effects of information and communication.

${ }^{17}$ This within-subjects design feature enables us to investigate the effect of variation in the audit probability on the accuracy of peer communication while controlling for subject heterogeneity.
} 
Each subject participates in only one treatment (session). The assignment of participants to treatments is completely randomized; all participants are drawn from the pool of potential subjects who had signed up for lab experiments. At the end of the session, the participants complete a short questionnaire by reporting some demographic information.

Participants are recruited from the pool of undergraduate students at the University of Tennessee - Knoxville, a large state university in the United States. Upon arrival at the laboratory, the participants are assigned to a computer station. The lab server assigns participants to groups (consisting of six to eight persons depending on the total number of participants in the session). The participants do not know who is in their group, only the number in their group, and they know that there are at least two groups in the session. ${ }^{18}$ Basic instructions are provided via hardcopy while the main instructions are provided via a series of screen images. After the practice rounds are completed, any final procedural questions are answered. Participants are not allowed to communicate with one another during the session except when allowed via the computer interface as a treatment. They are not told the exact duration of the experimental session, which is predetermined to last for 30 real rounds. Sessions take on average 90 minutes to complete. Participant earnings range from $\$ 19$ to $\$ 37$, depending upon task earnings, reporting behavior, and audit experience. Participants are told that payments will be made in private at the end of the session and that all responses are anonymous. ${ }^{19}$

\section{Results}

\footnotetext{
${ }^{18}$ Having multiple groups in a session increases anonymity for the participants.

${ }^{19}$ Recruiting is conducted through announcements and posters directing potential participants to sign up via a web page in which they post their contact information and the time blocks of availability. Participants are contacted via email, and are permitted to participate in only one tax experiment, although other experimental projects are ongoing at the time and participants may have participated in other types of experiments. We actively discourage "snowball" sampling in which recruited subjects bring additional subjects to a session. When we recruit, we do not reveal the exact nature of the experiment prior to the session.
} 
We begin with an analysis of the honesty of messages contingent on both the type of message and the results of the random audit process presented in Tables 2 and 3, respectively. Table 2 reports the honesty of messages over three domains. The fourth column reports the overall accuracy of each message, while the fifth and sixth columns report whether the messages were truthful about being audited or not and being compliant or not, respectively. As shown in Table 2, of the 2516 messages sent (excluding "No message"), 84.2 percent were truthful reports. However, the accuracy of the messages varies significantly by the type of message. Nearly all (99.4 percent) of Message 2 ("I was not audited") types were truthful; similarly, most individuals (91.6 percent) who sent Message 4 ("I was not audited and did not report all of my taxes") were honest. Even those who sent Message 5 ("I was not audited and reported all of my taxes") were mostly honest ( 84.6 percent). Indeed, these three messages $(2,4$, and 5$)$ were the most truthful of the various message types. Individuals therefore appear to convey largely honest and accurate information when the information indicates that they were not audited.

However, the accuracy of the messages changes significantly when the message conveys information that they were audited. The least truthful report was for Message 6 ("I was audited and did not report taxes"), where roughly one-half of all messages were untruthful; as the fifth and sixth columns indicate, most of the dishonesty in these messages was about their being audited rather than about their evasion behavior. ${ }^{20}$ Similarly, one-third of the individuals indicated that they were audited (Message 3, "I was audited"), when in fact they were not. Onefourth of the messages that indicated a subject was audited and reported all of their taxes (Message 7, "I was audited and reported all my taxes") were dishonest; roughly 50 percent of the dishonest messages were neither audited nor compliant, with the remainder equally dishonest

\footnotetext{
${ }^{20}$ Nearly 85 percent of the dishonest messages came from individuals who were engaged in tax evasion and who were not audited.
} 
about being audited (25 percent) and compliant ( 25 percent). Overall, the results in Table 2 suggest subjects were systematically dishonest about being audited when they were not. This result is consistent with the upward bias predicted by equation (5).

Systematic tendencies can also be observed by investigating the honesty of messages contingent on the actual experience and behavior of the subject. Table 3 explores three different contingencies, or circumstances: was the individual audited, did the individual engage in tax evasion, and was the audit policy (i.e., the audit probability) announced? Overall, compliant individuals send truthful messages on average 90 percent of the time, more so when the audit policy was publicly announced. However, individuals who engaged in tax evasion only sent accurate messages 80 percent of the time, and the proportion of honest messages decreased by roughly 10 percentage points when their evasion went undetected. Still, even those who dishonestly reported their earnings (to evade taxes) were mostly honest in their peer communication. Finally, individuals appear more honest when the audit probability is announced than when it is not announced, with the proportion of honest messages increasing from 79 percent to 87 percent, respectively.

Table 4 reports logistic regression analysis of the determinants of the truthfulness of messages, in order to determine if the differences reported in Tables 2 and 3 are significant. Results are reported for three different dependent variables: whether the message was truthful about being audited (Models 1 and 2), whether the message was truthful about being compliant (Models 3 and 4), and whether the message was entirely truthful (Models 5 and 6). ${ }^{21}$ In each case, the dependent variable in these regressions equals 1 if the message sent is truthful and 0 otherwise. Models 1, 3, and 5 include as explanatory variables several types of dummy variables:

\footnotetext{
${ }^{21}$ If the message did not contain any information about compliance behavior, then overall honesty is just honesty about the audit outcome.
} 
for the official announcement of the audit policy, the likelihood of an audit, for the compliance behavior of the taxpayer, for the audit results, and lagged dependent variables. Models 2, 4, and 6 also include interaction effects between factors as additional independent variables. All regressions report the results of logistic models estimated with subject-specific clustered error terms to account for the panel structure of the data.

The regression results lend support to the contingency analyses in Tables 2 and 3, and also reveal some behavioral interactions. Subjects who engaged in tax evasion are significantly less honest, as indicated by estimated coefficient for the dummy variable for tax evasion in Models 1, 2, and 5. Interestingly, their dishonesty is about being audited, not their evasion. However, taxpayers caught engaging in tax evasion send messages that are significantly more honest about being audited than either those whose tax evasion goes undetected or those that were compliant, as indicated by the interaction term in model 2 . Both of these results suggest that the reported audit rate exceeded the actual audit rate, and this is explored further below. Finally, subject honesty tends to be persistent, as demonstrated by the significance of the lagged dependent variables.

The results in Tables 2, 3, and 4 are indicative of an upward bias in the reported audit and compliance rates. Indeed, the theoretical framework predicts that the reported audit rate (i.e., the proportion of audits reported within a group) and the reported compliance rate (i.e., the proportion of subjects that claim to have reported all of their income) should both overstate the actual values, as reflected in Hypothesis 2, and that this bias should increase as the audit rate declines (Hypothesis 1). To explore these two hypotheses more systematically, Table 5 reports the actual and reported audit and compliance rates for each audit probability under both information treatments. In all but one case, both the reported audit and compliance rates exceed 
the actual results, and less so when the probability of an audit is announced, a result that is consistent with Hypothesis $2 .{ }^{22}$ Moreover, the upward bias in the reported audit rate increases as the audit probability decreases, as predicted by Hypothesis 1.

The tendency of the reported audit and compliance rates to overstate their actual values can also be seen in Figures 1 and 2, respectively. Figure 1 plots time series of the reported and actual audit rates pooled across sessions by the likelihood of audit; Figure 2 plots time series of the reported and actual compliance rates pooled across sessions by the likelihood of audit. Both figures reveal a tendency for the reported rates to exceed the actual values (Hypothesis 2).

Moreover, the difference between the reported and actual audit rates increases as the likelihood of audit approaches zero (Hypothesis 1).

Table 6 reports the results of logistic regression analysis of the truthfulness of messages based on the audit policy. Results are reported for two different dependent variables: the difference between the reported and actual audit results, and the difference between the reported and actual compliance behavior. Results are also reported under two different conditions, with and without a known audit policy. In each case, the dependent variable in these regressions equals 0 if the message sent is truthful, 1 if the message is dishonest about being audited/compliant, and -1 if the message is dishonest about not being audited/compliant. All models are estimated with dummy variables for the likelihood of an audit. All regressions are estimated with subject-specific clustered error terms to account for the panel structure of the data.

These results in Table 6 lend further support to Hypothesis 1: there is a tendency for the accuracy of messages regarding audit results to decline as the audit probability approaches zero,

\footnotetext{
${ }^{22}$ The actual compliance rate is slightly higher than the reported value when the unannounced audit probability is 30 percent, but the difference is not statistically significant.
} 
and this tendency is most pronounced when the likelihood of an audit is unknown. Note that the regression results in Table 4 suggest that the likelihood of an audit does not influence the likelihood of honest reporting. Rather, as the results in Tables 5 and 6 indicate, the likelihood of an audit influences the type of dishonesty, leading to an inflated perception of the audit rate. This finding is consistent with the increase in compliance reported by Alm, Jackson, and McKee (2009).

The regression results in Table 6 on the difference between the reported and actual compliance rates (Hypothesis 2) are somewhat less pronounced. Although the reported compliance rate exceeds the actual compliance rate in all but one case, the difference is only significant in two out of the eight cases. The increase in actual compliance rates seems most likely due to exaggerated audit rates, as opposed to inflated compliance rates, although it is important to remember that the anonymity offered in the laboratory environment is likely to facilitate more truthful reporting of compliance behavior than one might expect in the field. Hence, it is still possible that both factors influence compliance in the field.

\section{Conclusions}

Previous work by Alm, Jackson, and McKee (2009) has shown that participants in the tax reporting exercise respond to both official and unofficial information on past enforcement effort. Signals, formal and informal, that the enforcement level has increased lead subjects to report higher tax compliance. In this paper we use data from these same laboratory experiments to show that reliance on unofficial information is not misplaced. For the most part, taxpayers communicate honestly in their unofficial messages to other taxpayers about tax agency 
enforcement efforts. Even so, there are also systematic factors that influence the honesty of selfreported information.

In particular, our results suggest that individuals often send truthful messages about their own audit experience and compliance behavior, even though they have no financial or strategic incentive to convey such truthful information; that is, more than 80 percent of messages report accurate information to fellow taxpayers. Still, our results also indicate that individuals tend to overstate the audit risk via untruthful messages about being audited, sending messages that they were audited when in fact they were not audited, perhaps in an attempt to improve the social norm of group compliance. We also observe a significant increase in the accuracy of selfreported information after being caught evading taxes; tax evaders who are not audited are significantly less honest about being audited. Interestingly, these same tax evaders are significantly more honest about their compliance behavior. Perhaps these differences in honesty among tax evaders are motivated by feelings of guilt, and dishonest individuals may attempt to overstate the audit risk as a means to make amends.

Overall, our results clearly indicate the importance of information. Most of our theories of individual tax compliance behavior - indeed, many of our theories of individual behavior more broadly - rely in some form upon individuals knowing the true incentives that they face. However, the ways in which individuals learn of these incentives remain largely unknown. Our results are among the first to demonstrate the link between the information reported by individuals and the honesty of this information. These results help to inform the discussion of the role of informal information networks.

\section{$\underline{\text { References }}$}


Allingham, M., \& Sandmo, A. (1972). Income tax evasion: A theoretical analysis. Journal of Public Economics, 1 (4), 323-228.

Alm, J. (2012). Measuring, explaining, and controlling tax evasion: Lessons from theory, experiments, and field studies. International Tax and Public Finance, 19 (1), 54-77.

Alm, J., Bloomquist, K. M., \& McKee, M. (2015). On the external validity of laboratory tax compliance experiments. Economic Inquiry, 53 (2), 1170-1186.

Alm, J., Bloomquist, K. M., \& McKee, M. (2016). When you know your neighbor pays taxes: Information, peer effects, and tax compliance." Fiscal Studies, forthcoming.

Alm, J., Jackson, B. R., \& McKee, M. (1992). Institutional uncertainty and taxpayer compliance. The American Economic Review, 82 (4), 1018-1026.

Alm, J., Jackson, B. R., \& McKee, M. (2009). Getting the word out: Increased enforcement, audit information dissemination, and compliance behavior. Journal of Public Economics, 93 (3-4), 392-402.

Alm, J., McClelland, G. H., \& Schulze, W. D. (1992). Why do people pay taxes? Journal of Public Economics, 48 (1), 21-38.

Alm, J., McClelland, G. H., \& Schulze, W. D. (1999). Changing the social norm of tax compliance by voting. Kyklos, 52, 141-171.

Alm, J., \& McKee, M. (2004). Tax compliance as a coordination game. Journal of Economic Behavior and Organization, 54 (3), 297-312.

Alm, J., \& McKee, M. (2006). Audit certainty, audit productivity, and taxpayer compliance. National Tax Journal, 59 (4), 801-816.

Alm, J., \& Torgler, B. (2011). Do ethics matter? Tax compliance and morality. Journal of Business Ethics, 101 (4), 635-651.

Andreoni, J. (1991). Reasonable doubt and the optimal magnitude of fines: Should the penalty fit the crime? RAND Journal of Economics, 22 (3), 385-395.

Andreoni, J., Erard, B., \& Feinstein, J. S. (1998). Tax compliance. The Journal of Economic Literature, 36 (2), 818-860.

Becker, G. S. (1968). Crime and punishment - An economic approach. The Journal of Political Economy, 76 (2), 169-217.

Becker, W., Buchner, H.-J., \& Sleeking, S. (1987). The impact of public transfer expenditures on tax evasion: An experimental approach. Journal of Public Economics, 34 (2), 243-252.

Cappelen, A. W., Sørensen, E. Ø., \& Tungodden, B. (2013). When do we lie? Journal of Economic Behavior and Organization, 93, 258-265.

Childs, J. (2012). Gender differences in lying. Economics Letters, 114 (2), 147-149.

Cojoc, D., \& Stoian, A. (2014). Dishonesty and charitable behavior. Experimental Economics, 17 (4), 717-732.

Conrads, J., Irlenbusch, B., Rilke, R. M., \& Walkowitz, G. (2013). Lying and team incentives. Journal of Economic Psychology, 34, 1-7.

DeGroot, M. H. (1970). Optimal Statistical Decisions. New York, NY: McGraw-Hill Book Company, Inc.

Dreber, A., \& Johannesson, M. (2008). Gender differences in deception. Economics Letters, 99 (1), 197-199.

Erard, B., \& Feinstein, J. S. (1994). Honesty and evasion in the tax compliance game. The RAND Journal of Economics, 25 (1), 1-19.

Frey, B. S. (1992). Tertium datur: Pricing, regulating, and intrinsic motivation. Kyklos, 45 (2), 164-184. 
Frey, B. S. (1997). Not Just for the Money: An Economic Theory of Personal Motivation. Cheltenham, UK and Lyme, NH: Edward Elgar Publishers.

Gächter, S., \& Schulz, J. F. (2016). Intrinsic honesty and the prevalence of rule violations across societies. Nature, 531, 496-499.

Glätzle-Rützler, D., \& Lergetporer, P. (2015). Lying and age: An experimental study. Journal of Economic Psychology, 46, 12-25.

Gneezy, U. (2005). Deception: The role of consequences. The American Economic Review, 95 (1), 384-394.

Gneezy, U., Rockenbach, B., \& Serra-Garcia, M. (2013). Measuring lying aversion. Journal of Economic Behavior and Organization, 93, 293-300.

Gylfason, H., Arnardottir, A. A., \& Kristinsson, K. (2013). More on gender differences in lying, Economics Letters, 119 (1), 94-96.

Holm, H. J., \& Kawagoe, T. (2010). Face-to-face lying - An experimental study in Sweden and Japan. Journal of Economic Psychology, 31 (3), 310-321.

Kirchler, E. (2007). The Economic Psychology of Tax Behavior. Cambridge, UK: Cambridge University Press.

Lundquist, T., Ellingsen, T., Gribbe, E., \& Johannesson, M. (2009). The aversion to lying. Journal of Economic Behavior and Organization, 70 (1), 81-92.

Oei, S.-Y., \& Ring, D. M. (2016). Can sharing be taxed? Washington University Law Review, 93 (4), 1-82.

Plott, C. R. (1987). Dimensions of parallelism: Some policy applications of experimental methods. In A. E. Roth (Ed.), Laboratory Experimentation in Economics: Six Points of View. New York, NY: Cambridge University Press, 193-229.

Rosenbaum, S. M., Billinger, S., \& Stieglitz, N. (2014). Let's be honest: A review of experimental evidence on honesty and truth telling. Journal of Economic Psychology, 45, 181-196.

Sandmo, A. (2012). An evasive topic: Theorizing about the hidden economy. International Tax and Public Finance, 19 (1), 5-24.

Slemrod, J., \& Yitzhaki, S. (2002). Tax avoidance, evasion, and administration. In A. J. Auerbach \& M. Feldstein (Eds.), Handbook of Public Economics, Volume 3. Amsterdam, London, and New York: Elsevier, 1423-1470.

Smith, V. L. (1982). Microeconomic systems as an experimental science. The American Economic Review, 72 (4), 923-955.

Smith, V. L., \& Walker, J. (1993). Monetary rewards and decision cost in experimental economics. Economic Inquiry, 31 (2), 245-261.

Sutter, M. (2009). Deception through telling the truth?! Experimental evidence from individuals and teams. The Economic Journal, 119 (534), 47-60.

Torgler, B. (2002). Speaking to theorists and searching for facts: Tax morale and tax compliance in experiments. Journal of Economic Surveys, 16 (5), 657-683.

Torgler, B. (2007). Tax Compliance and Tax Morale: A Theoretical and Empirical Analysis. Cheltenham, UK: Edward Elgar Publishers.

Wenzel, M. (2005). Misperceptions of social norms about tax compliance: From theory to intervention. Journal of Economic Psychology, 26 (6), 862-883.

Wenzel, M. (2004). An analysis of norm processes in tax compliance. Journal of Economic Psychology, 25 (2), 213-228. 
Table 1. Experimental Design and Aggregate Results

\begin{tabular}{|c|c|}
\hline \multicolumn{2}{|c|}{ Official Audit Policy Announced? } \\
\hline Treatment A & Treatment B \\
Yes - Official audit policy is announced & No - Official audit policy is not announced \\
\hline Subjects $=62$ & Subjects $=40$ \\
Compliance Rate $=0.516$ & Compliance Rate $=0.649$ \\
Audit Yield $=\$ 17.67$ & Audit Yield $=\$ 15.04$ \\
\hline
\end{tabular}

Notes: In both Treatments A and B, subjects are allowed to send unofficial messages; see Table 2. All sessions last 30 rounds. Common to all treatments are the following parameters: the tax rate is 0.35 ; the fine rate is 1.5; subjects are organized into groups of six to eight persons; the income range is from a maximum of 100 lab dollars to a minimum is 60 lab dollars in increments of 10 lab dollars; and audit rates vary from 0.05 to 0.40 . The Compliance Rate is calculated as (Tax Paid/Tax Owed), and the Audit Yield is calculated as the average penalty assessed in an audit.

Table 2. Unofficial Messages Allowed

\begin{tabular}{|c|c|c|c|c|c|}
\hline Message & Message Content & $\begin{array}{c}\text { Number (Percent) of } \\
\text { Messages Sent }\end{array}$ & $\begin{array}{c}\text { Accuracy of } \\
\text { Messages }\end{array}$ & $\begin{array}{c}\text { Audit } \\
\text { Accuracy }\end{array}$ & $\begin{array}{c}\text { Compliance } \\
\text { Accuracy }\end{array}$ \\
\hline 1 & No message & $\begin{array}{c}544 \\
(17.8 \%)\end{array}$ & --- & --- & --- \\
\hline 2 & I was not audited & $\begin{array}{c}681 \\
(22.3 \%)\end{array}$ & $99.4 \%$ & $99.4 \%$ & --- \\
\hline 3 & I was audited & $\begin{array}{c}281 \\
(9.2 \%)\end{array}$ & $67.6 \%$ & $67.6 \%$ & --- \\
\hline 4 & $\begin{array}{l}\text { I was not audited and did } \\
\text { not report all my taxes }\end{array}$ & $\begin{array}{c}549 \\
(17.9 \%)\end{array}$ & $91.6 \%$ & $97.6 \%$ & $92.9 \%$ \\
\hline 5 & $\begin{array}{l}\text { I was not audited and } \\
\text { reported all my taxes }\end{array}$ & $\begin{array}{c}558 \\
(18.2 \%)\end{array}$ & $84.6 \%$ & $97.0 \%$ & $86.2 \%$ \\
\hline 6 & $\begin{array}{l}\text { I was audited and did not } \\
\text { report all my taxes }\end{array}$ & $\begin{array}{c}253 \\
(8.3 \%)\end{array}$ & $51.8 \%$ & $52.6 \%$ & $92.5 \%$ \\
\hline 7 & $\begin{array}{l}\text { I was audited and } \\
\text { reported all my taxes }\end{array}$ & $\begin{array}{c}194 \\
(6.4 \%)\end{array}$ & $74.7 \%$ & $82.0 \%$ & $81.4 \%$ \\
\hline Total & & $\begin{array}{c}3060 \\
(100 \%)\end{array}$ & $84.2 \%$ & $88.9 \%$ & $89.0 \%$ \\
\hline
\end{tabular}

Notes: In both Treatments A and B, all subjects are permitted to send one message from this list in each period, and each must make a choice of message (including the decision to send no message, or Message $1)$ before they can proceed to the end of the current period. The overall percent of accurate messages $(84.2 \%)$ is based on the number of informational messages sent; this calculation excludes Message 1 ("No message"). There are 2516 (=3060-544) informational messages (or instances of Messages 2 to 7). 
Table 3. Percentage of Truthful Messages, Contingent on Circumstance ${ }^{\text {a }}$

\begin{tabular}{|c|c|c|c|c|c|}
\hline \multirow{3}{*}{$\begin{array}{c}\text { Compliance } \\
\text { Behavior }\end{array}$} & \multicolumn{2}{|c|}{$\begin{array}{c}\text { Treatment A } \\
\text { Official Audit Policy Announced }\end{array}$} & \multicolumn{2}{c|}{$\begin{array}{c}\text { Treatment B } \\
\text { Audit Policy Not Announced }\end{array}$} & \\
\cline { 2 - 5 } & \multicolumn{2}{|c|}{ Audit Results } & \multicolumn{2}{|c|}{ Audit Results } & \\
\cline { 2 - 5 } & Audited & Not Audited & Audited & Not Audited & Overall \\
\hline \multirow{2}{*}{ Complied } & $93.3 \%$ & $95.2 \%$ & $89.3 \%$ & $83.4 \%$ & $90.7 \%$ \\
& $(134)$ & $(455)$ & $(103)$ & $(314)$ & $(1006)$ \\
\hline \multirow{2}{*}{ Evaded } & $90.7 \%$ & $80.8 \%$ & $86.9 \%$ & $72.1 \%$ & $79.9 \%$ \\
& $(172)$ & $(801)$ & $(107)$ & $(430)$ & $(1510)$ \\
\hline \multirow{2}{*}{ Overall } & $91.8 \%$ & $86.0 \%$ & $88.1 \%$ & $76.9 \%$ & $84.2 \%$ \\
& $(306)$ & $(1256)$ & $(210)$ & $(744)$ & $(2516)$ \\
\hline
\end{tabular}

${ }^{\mathrm{a}}$ Sample sizes are in parentheses. Because each subject participates in 30 rounds, the observations are not independent.

Table 4. Regression Analysis of Honesty of Messages by Experience and Behavior

\begin{tabular}{|c|c|c|c|c|c|c|}
\hline \multirow[b]{3}{*}{ Variable } & \multicolumn{2}{|c|}{ Audit Truth } & \multicolumn{2}{|c|}{ Compliance Truth } & \multicolumn{2}{|c|}{ Overall Truth } \\
\hline & \multicolumn{2}{|c|}{ Audit Policy } & \multicolumn{2}{|c|}{ Audit Policy } & \multicolumn{2}{|c|}{ Audit Policy } \\
\hline & (1) & (2) & (3) & (4) & (5) & (6) \\
\hline Intercept & -0.423 & -0.235 & $-1.635^{* *}$ & $-1.837 * * *$ & $-1.239 * * *$ & $-1.248 * *$ \\
\hline & $(0.386)$ & $(0.538)$ & $(0.647)$ & $(0.673)$ & $(0.414)$ & $(0.492)$ \\
\hline $\begin{array}{l}\text { 5\% Audit Probability } \\
(=1 \text { if Audit Probability is 5\%) }\end{array}$ & $\begin{array}{c}0.238 \\
(0.328)\end{array}$ & $\begin{array}{c}0.313 \\
(0.352)\end{array}$ & $\begin{array}{c}0.450 \\
(0.457)\end{array}$ & $\begin{array}{c}0.474 \\
(0.447)\end{array}$ & $\begin{array}{l}0.546 * \\
(0.298)\end{array}$ & $\begin{array}{l}0.617 * \\
(0.328)\end{array}$ \\
\hline $\begin{array}{l}\text { 10\% Audit Probability } \\
(=1 \text { if Audit Probability is } 10 \%)\end{array}$ & $\begin{array}{l}-0.098 \\
(0.278)\end{array}$ & $\begin{array}{l}-0.101 \\
(0.300)\end{array}$ & $\begin{array}{c}0.077 \\
(0.418)\end{array}$ & $\begin{array}{c}0.163 \\
(0.378)\end{array}$ & $\begin{array}{l}-0.003 \\
(0.254)\end{array}$ & $\begin{array}{l}-0.018 \\
(0.260)\end{array}$ \\
\hline $\begin{array}{l}30 \% \text { Audit Probability } \\
\text { (=1 if Audit Probability is } 30 \% \text { ) }\end{array}$ & $\begin{array}{c}0.094 \\
(0.313)\end{array}$ & $\begin{array}{c}0.022 \\
(0.332)\end{array}$ & $\begin{array}{l}-0.186 \\
(0.435)\end{array}$ & $\begin{array}{l}-0.138 \\
(0.425)\end{array}$ & $\begin{array}{l}-0.003 \\
(0.298)\end{array}$ & $\begin{array}{l}-0.098 \\
(0.316)\end{array}$ \\
\hline $\begin{array}{l}\text { Audit Policy Announced? } \\
(=1 \text { if Treatment A) }\end{array}$ & $\begin{array}{c}0.458 \\
(0.311)\end{array}$ & $\begin{array}{c}0.743 \\
(0.606)\end{array}$ & $\begin{array}{l}0.783^{*} \\
(0.424)\end{array}$ & $\begin{array}{c}1.113 \\
(0.784)\end{array}$ & $\begin{array}{c}0.457 \\
(0.289)\end{array}$ & $\begin{array}{l}1.067 * \\
(0.578)\end{array}$ \\
\hline $\begin{array}{l}\text { Audited? } \\
\text { (=1 if subject was audited) }\end{array}$ & $\begin{array}{c}0.847 \\
(0.656) \\
\end{array}$ & $\begin{array}{l}-0.774 \\
(0.694) \\
\end{array}$ & $\begin{array}{c}0.318 \\
(0.343) \\
\end{array}$ & $\begin{array}{c}0.071 \\
(0.495) \\
\end{array}$ & $\begin{array}{c}1.310^{* * *} \\
(0.491)\end{array}$ & $\begin{array}{l}-0.225 \\
(0.532)\end{array}$ \\
\hline $\begin{array}{l}\text { Evaded? } \\
(=1 \text { if subject evaded taxes })\end{array}$ & $\begin{array}{c}-0.716^{* *} \\
(0.283)\end{array}$ & $\begin{array}{c}-1.146 * * \\
(0.520)\end{array}$ & $\begin{array}{l}-0.031 \\
(0.580)\end{array}$ & $\begin{array}{c}0.456 \\
(0.809)\end{array}$ & $\begin{array}{l}-0.664^{*} \\
(0.351)\end{array}$ & $\begin{array}{l}-0.884 \\
(0.567)\end{array}$ \\
\hline $\begin{array}{l}\text { Audit Policy Announced and Audited? } \\
(=1 \text { if subject was audited in Treatment A) }\end{array}$ & & $\begin{array}{l}-0.443 \\
(1.080)\end{array}$ & & $\begin{array}{c}0.961 \\
(0.654)\end{array}$ & & $\begin{array}{l}-0.681 \\
(0.725)\end{array}$ \\
\hline $\begin{array}{l}\text { Audit Policy Announced and Evaded? } \\
(=1 \text { if subject evaded in Treatment A) }\end{array}$ & & $\begin{array}{l}-0.306 \\
(0.557)\end{array}$ & & $\begin{array}{l}-0.853 \\
(1.139)\end{array}$ & & $\begin{array}{l}-0.672 \\
(0.650)\end{array}$ \\
\hline $\begin{array}{l}\text { Audited and Evaded? } \\
(=1 \text { if subject evaded and was audited) }\end{array}$ & & $\begin{array}{l}2.918 * * \\
(1.183)\end{array}$ & & $\begin{array}{l}-0.364 \\
(0.680)\end{array}$ & & $\begin{array}{l}2.811 * * * \\
(0.745)\end{array}$ \\
\hline $\begin{array}{l}\text { Lagged Audit Truth } \\
(=1 \text { if subject was truthful in the previous round) }\end{array}$ & $\begin{array}{l}3.451 * * * \\
(0.257)\end{array}$ & $\begin{array}{l}3.637 * * * \\
(0.333)\end{array}$ & & & & \\
\hline $\begin{array}{l}\text { Lagged Compliance Truth } \\
(=1 \text { if subject was truthful in the previous round) }\end{array}$ & & & $\begin{array}{c}4.656 * * * \\
(0.555)\end{array}$ & $\begin{array}{c}4.648 * * * \\
(0.546)\end{array}$ & & \\
\hline $\begin{array}{l}\text { Lagged Truth } \\
(=1 \text { if subject was truthful in the previous round) }\end{array}$ & & & & & $\begin{array}{c}4.098 * * * \\
(0.292)\end{array}$ & $\begin{array}{c}4.309 * * * \\
(0.302)\end{array}$ \\
\hline Number of Observations & 2295 & 2295 & 1297 & 1297 & 2295 & 2295 \\
\hline Log-Likelihood & -537.219 & -519.244 & -221.520 & -219.441 & -552.402 & -533.294 \\
\hline
\end{tabular}

Notes: The dependent variable in Models 1 and 2 equals 1 if the message was truthful about being audited (Audit

Truth); the dependent variable in Models 3 and 4 equals 1 if the message was truthful about being compliant (Compliance Truth); and the dependent variable in Models 5 and 6 equals 1 if the message was accurate about both being audited and being compliant (Overall Truth). In all cases, null messages are not included. Subjectspecific clustered standard errors are reported in parentheses. Statistical significance is indicated by asterisks, with $*$, **, and *** denoting significance at the $10 \%, 5 \%$ and $1 \%$ levels, respectively. 
Table 5: Reported and Actual Audit and Compliance Rates by Audit Policy and Information Treatment ${ }^{\text {a }}$

\begin{tabular}{|c|c|c|c|c|c|c|c|c|}
\hline & \multicolumn{4}{|c|}{ Audit Policy Announced } & \multicolumn{3}{c|}{ Audit Policy Not Announced } \\
\hline & \multicolumn{2}{|c}{ Audit Rate } & \multicolumn{2}{c|}{ Compliance Rate } & \multicolumn{2}{c|}{ Audit Rate } & \multicolumn{2}{c|}{ Compliance Rate } \\
\hline $\begin{array}{c}\text { Chance of } \\
\text { an Audit }\end{array}$ & Reported & Actual & Reported & Actual & Reported & Actual & Reported & Actual \\
\hline $5 \%$ & $10.8 \%$ & $2.9 \%$ & $20.9 \%$ & $16.0 \%$ & $28.9 \%$ & $5.56 \%$ & $26.5 \%$ & $11.7 \%$ \\
& $(369)$ & $(480)$ & $(187)$ & $(480)$ & $(152)$ & $(180)$ & $(83)$ & $(180)$ \\
\hline $10 \%$ & $16.9 \%$ & $8.7 \%$ & $52.1 \%$ & $41.6 \%$ & $23.7 \%$ & $12.1 \%$ & $53.5 \%$ & $57.6 \%$ \\
& $(390)$ & $(450)$ & $(257)$ & $(450)$ & $(317)$ & $(420)$ & $(198)$ & $(420)$ \\
\hline $30 \%$ & $34.5 \%$ & $28.0 \%$ & $58.7 \%$ & $51.8 \%$ & $36.4 \%$ & $28.9 \%$ & $45.0 \%$ & $43.6 \%$ \\
& $(397)$ & $(450)$ & $(298)$ & $(450)$ & $(286)$ & $(360)$ & $(200)$ & $(360)$ \\
\hline $40 \%$ & $40.9 \%$ & $35.8 \%$ & $51.2 \%$ & $42.3 \%$ & $48.2 \%$ & $44.2 \%$ & $70.1 \%$ & $53.3 \%$ \\
& $(406)$ & $(480)$ & $(244)$ & $(480)$ & $(199)$ & $(240)$ & $(87)$ & $(240)$ \\
\hline
\end{tabular}

${ }^{a}$ Sample sizes are in parentheses. Because each subject participates in 30 rounds, the observations are not independent. Statistical significance of tests of difference in reported and actual proportions are indicated by asterisks with $*, * *$, and $* * *$ denoting significance at the $10 \%, 5 \%$ and $1 \%$ levels, respectively.

Table 6. Regression Analysis of Audit and Compliance Rates

\begin{tabular}{|l|c|c|c|c|}
\hline & \multicolumn{2}{|c|}{ Audit Rate Bias } & \multicolumn{2}{c|}{ Compliance Rate Bias } \\
\hline Variable & Policy Known & Policy Unknown & Policy Known & Policy Unknown \\
\hline 40\% Audit Probability & 0.042 & 0.040 & 0.012 & 0.057 \\
(=1 if Audit Probability is 40\%) & $(0.031)$ & $(0.054)$ & $(0.042)$ & $(0.114)$ \\
\hline $30 \%$ Audit Probability & $0.060^{*}$ & $0.087 *$ & 0.030 & 0.015 \\
(=1 if Audit Probability is 30\%) & $(0.031)$ & $(0.039)$ & $(0.049)$ & $(0.084)$ \\
\hline 10\% Audit Probability & $0.087^{*} *$ & $0.126^{*}$ & $0.093^{*}$ & -0.025 \\
(=1 if Audit Probability is 10\%) & $(0.043)$ & $(0.066)$ & $(0.055)$ & $(0.082)$ \\
\hline 5\% Audit Probability & $0.076^{*}$ & $0.237 * *$ & $0.064^{*}$ & 0.048 \\
(=1 if Audit Probability is 5\%) & $(0.031)$ & $(0.109)$ & $(0.038)$ & $(0.080)$ \\
\hline Number of Observations & 1562 & 954 & 986 & 568 \\
R-Squared & 0.053 & 0.113 & 0.041 & 0.007 \\
\hline
\end{tabular}

Notes: The dependent variable in columns 2 and 3 equals 0 if the message was truthful about being audited, equals 1 if the message dishonestly indicated the subject was audited, and equals -1 if the message dishonestly indicated the subject was not audited; the dependent variable in columns 4 and 5 equals 0 if the message was truthful about being compliant, equals 1 if the message dishonestly indicated the subject was compliant, and equals -1 if the message dishonestly indicated the subject evaded. In all cases, null messages are not included. Subject-specific clustered standard errors are reported in parentheses. Statistical significance is indicated by asterisks, with *, **, and *** denoting significance at the $10 \%, 5 \%$ and $1 \%$ levels, respectively. 
Figure 1. Time Series of Reported Versus Actual Audit Rate
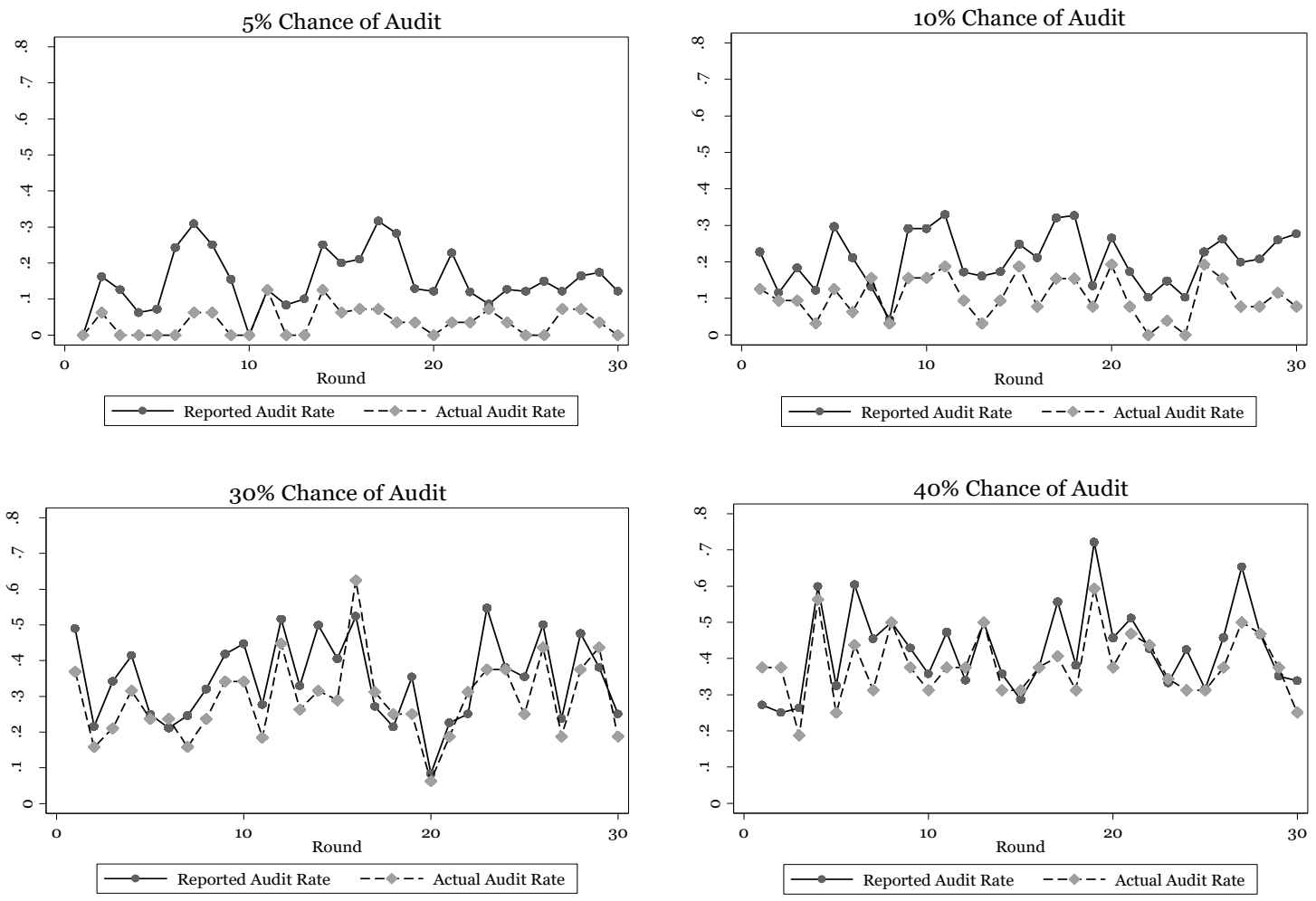

Figure 2. Time Series of Reported Versus Actual Compliance Rate
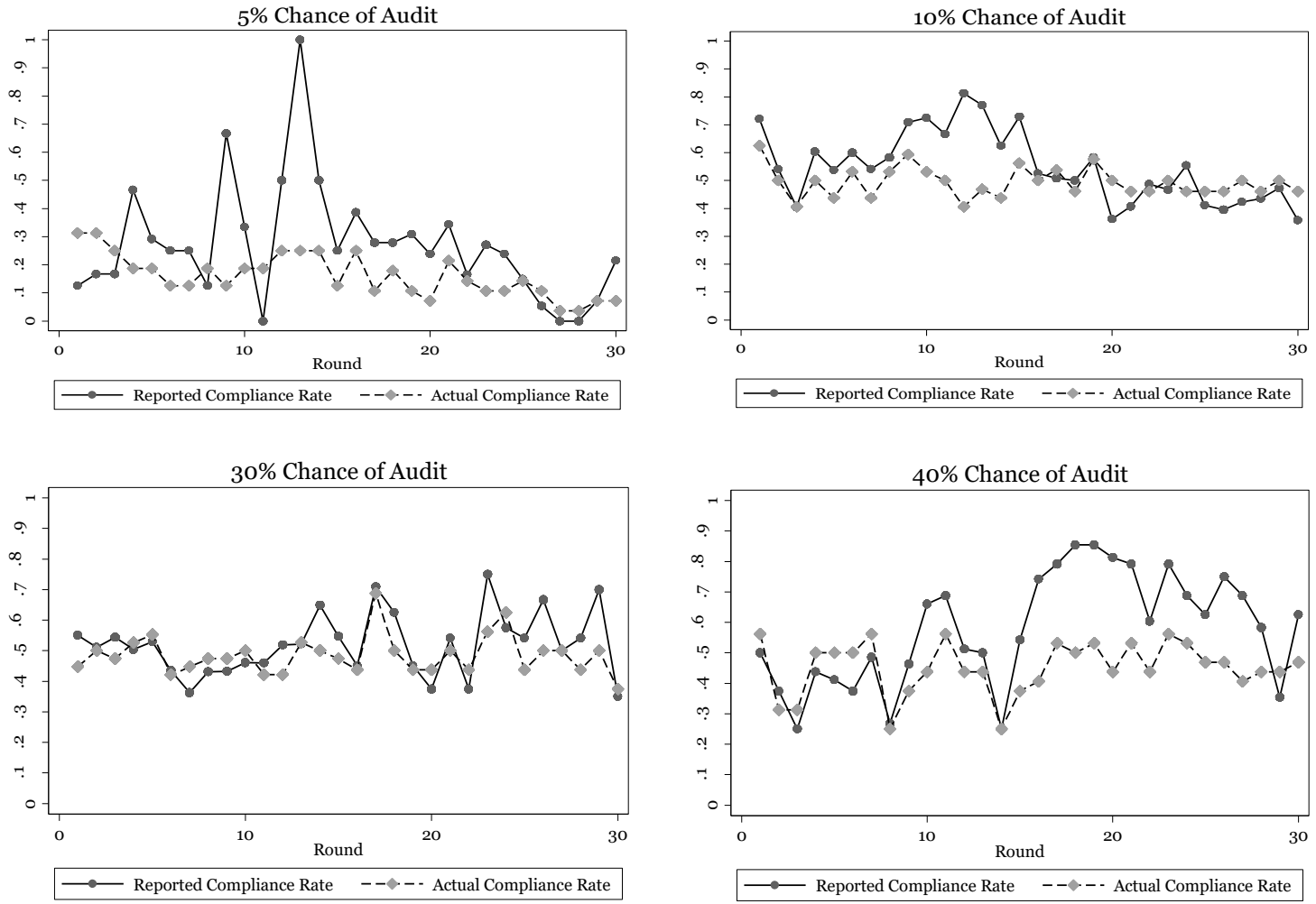